\title{
Discussion on Talent Training Mechanism of "New Engineering” in Local Colleges and Universities
}

\author{
Xuehua Jiang \\ Faculty of Engineering \\ Linyi University \\ Linyi, China \\ jxhyx@163.com
}

\author{
Peijiang Chen \\ School of Mechanical and Vehicle Engineering \\ Linyi University \\ Linyi, China \\ chenpeijiang@163.com
}

\author{
Xingqiang Zhang \\ School of Automation and Electrical Engineering \\ Linyi University \\ Linyi, China \\ zhangxingqiang@lyu.edu.cn
}

\begin{abstract}
The technological revolution has promoted industrial transformation, in order to meet the needs of the development of new economy, new technology and new industry, the state has implemented the major strategies of innovation driven development and "China Manufacturing 2025". China's higher education has started the construction of "new engineering". For the construction of "new engineering", local colleges and universities must take active and effective measures, change the educational concept, improve the curriculum system, strengthen the construction of teachers, build a platform for education integration and education, and improve the protection mechanism of talent training, so as to better cultivate engineering talents who are competent for economic development and industrial transformation.
\end{abstract}

Keywords-Local colleges and universities; New engineering; Talent training; Mechanism

\section{INTRODUCTION}

To take the initiative to deal with a new round of technological revolution and the industrial revolution, the national implementation of the innovation driven development and "2025 Chinese manufacturing", "Internet plus", "big data", "cloud computing" and a series of national strategy, for the training of engineering talents scientific foundation, engineering capacity, high comprehensive quality response the strategic needs of the country It is of great practical and strategic significance to the vigorous development of the new economy, which is characterized by new technology, new industry, new industry and new model. It is also an important prerequisite for building a powerful manufacturing country and an innovative country.

In this context, higher requirements for engineering science and technology personnel are put forward, and the innovation of engineering education reform is urgently needed. As the "2.0 edition of the education and training plan for excellent engineers", the construction of "new engineering" is also officially opened after "Fudan consensus" and "Tianda action".

This study was supported by the Teaching Quality Engineering Projects of Linyi University in 2014, 2016 and 2017.
The proposal of "new engineering" points out a new direction for the improvement of the quality of engineering talents, including applied undergraduate talents, and puts forward new challenges for engineering education in China. The engineering education will inevitably change in all directions and the mode of talent training will also change. Local colleges and universities should take the initiative to connect regional economic development and industrial transformation, build a scientific and reasonable quality guarantee mechanism for talent training, and cultivate applied talents with industry knowledge, engineering practice ability and industrial development demand.

\section{THE CONNOTATION AND SIGNIFICANCE OF THE CONSTRUCTION OF "NEW ENGINEERING"}

\section{A. The connotation and construction goal of "new engineering"}

"New engineering", "Engineering" is the essence, "new" is the orientation. Compared with the old engineering, the "new engineering" emphasizes the practicality, intersecting and comprehensiveness of the subject. It pays particular attention to the close combination of new technologies such as information communication, electronic control, software design and traditional industrial technology. It is summed up as "five new", that is, the new concept of engineering education, the new structure of subject and specialty, the new mode of personnel training, the new quality of education and teaching, and the new system of classified development. By exploring the new paradigm of engineering development, colleges and universities are exploring the new paradigm of engineering development, setting up professional needs and building a new structure of engineering specialty, asking the content of technology development, updating the knowledge system of engineering talents, asking students to change their interests and innovating the ways and means of Engineering Education, and asking the main body of the school to push the reform to explore the self development and self excitation of the new 
engineering department. The construction of "new engineering" should be done in seven aspects, such as building a new ecology of engineering education, opening up and integrating engineering education, asking international frontier standards and enhancing the international competitiveness of engineering education [1].

\section{B. "New engineering" construction is an inevitable requirement to adapt to industrial transformation and upgrading.}

China's economic development is at a critical stage of structural adjustment, transformation and upgrading, and the new round of technology and industrial revolution taking the Internet as the core is ready for development. Engineering education is closely related to industrial development and supports each other. The development of new industries relies on engineering education to provide talent support. It can be said that doing a good job in the active layout and deepening reform of engineering education will certainly play a positive role in promoting economic transformation and upgrading; otherwise, it will slow down the process of industrial upgrading. The development of the new engineering must be based on the needs of the industry, with a strong goal orientation and problem oriented, to understand the current situation of the industry, to find out the existing problems in the industry, and to train the engineering talents in accordance with the requirements of the times and the industry[2].

\section{C. "New engineering" construction is an important way to enhance national competitiveness.}

In order to cope with the challenges of the financial crisis and revitalize the real economy, the major developed countries have issued a forward-looking strategic report on the reform of engineering education, and actively promote innovation in the reform of engineering education. We should promote the transformation of the national and regional industrial structure and realize the core elements of the transformation from the traditional economy to the new economy, and to speed up the training of "new engineering" talents to meet the needs of industrial transformation and upgrading. In order to respond to the national strategic demand, support the vigorous development of the new service economy, break through the core technology, build the post advantage, occupy the strategic commanding point in the future global innovation ecosystem, and urgently need to train a large number of new engineering talents with stronger innovation ability, change ability and adaptability to serve the national strategy. It will further enhance the overall strength and international competitiveness of China's engineering education[3].

\section{The construction of "new engineering" is a realistic demand for reforming higher engineering education.}

The national implementation of the "China manufacturing 2025", "Internet plus" innovation driven development strategy is based on global industrial pattern depth adjustment, according to the current development level of China's manufacturing industry, to promote our country manufacturing industry to break the development of the ten areas from a new generation of information technology, to rapid development
China's manufacturing industry. The national implementation of the "China manufacturing 2015", "Internet plus" innovation driven development strategy is based on global industrial pattern depth adjustment, according to the current development level of China's manufacturing industry, the first to promote the development of China's manufacturing industry from the ten major areas of a new generation of information technology, etc. It provides the best opportunity for the rapid development of China's manufacturing industry and the transformation and upgrading of our country. It also puts forward new challenges to the higher engineering education in China, especially for the multi-level engineering personnel training to meet the adjustment of domestic and foreign market demand. The construction of "new engineering" needs to change ideas and speed up the education concept of green development, inclusive development and harmonious development. It needs solid professional technology to cultivate more engineering and technical talents with overall view, engineering view, scientific view and social view.

\section{PROMOTING THE CONSTRUCTION OF "NEW} ENGINEERING" AND MEASURES TO BE TAKEN BY LOCAL COLLEGES AND UNIVERSITIES

\section{A. Changing the concept of training education for the purpose of training technical talents}

At present, the local applied undergraduate education is generally incompatible with the needs of the talent training and the actual needs of the society. The training program for professional talents is short of the application features, the process of education places emphasis on theory rather than practice, and the graduates lack the ability to apply the professional knowledge to the actual engineering. The construction of "new engineering" has put forward new requirements for engineering education in China. The educators in Colleges and universities should fully realize the urgency and necessity of the construction of "new engineering", and make clear their roles and responsibilities in the training of "new engineering" talents. We should set up the correct concept of applied talents training, recognize the situation, face difficulties and make progress. Actively participate in the "new engineering" construction, through training and learning to improve their professional practice ability and practical teaching level[2].

\section{B. Setting up discipline and specialty layout based on the demand of industrial transformation}

"New engineering" is a new industry. Local colleges and universities must take regional industrial demand as the guidance, take the initiative to connect regional economic development and industrial transformation. It is necessary to take the concept of "new engineering" as the guidance, grasp the direction of the demand for talents of the industry, rearrange the layout of the professional structure, set up newlydeveloping, new-style and newborn disciplines, rearrange the professional layout. Let students take the initiative to adapt themselves to the leading, blending, innovation and development of new engineering. In time to train the outstanding engineering talents who can lead the future 
industry development and have the ability of innovation and entrepreneurship, we can effectively train the applied compound talents with technological innovation and industrial innovation. We should strengthen the construction of professional connotation, and vigorously construct the professional setting and dynamic adjustment mechanism of the engineering education of "government guidance, university mainly, active participation of the industry and multiple evaluation of the society".

\section{Optimizing training plan based on engineering capability training}

The industrial revolution has promoted industrial transformation. Whether new economy or new industry, new engineering, it is a broad knowledge and technologically advanced interdisciplinary engineering concept. The industrial revolution has promoted industrial transformation. Whether new economy or new industry is new engineering, it is a broad knowledge and technologically advanced interdisciplinary engineering concept. Therefore, modern engineering is a combination of multi-disciplinary knowledge system integration, showing a highly integrated and cross-border trend of knowledge and technology. From the perspective of engineering talent demand, industrial transformation requires engineering talents with new technology. It is necessary to revise and improve the training program for the talents of engineering major, and to reconstruct the training model according to the requirements of the training objectives, the requirements of graduation, the course setting, the practice teaching and so on[4].

\section{Strengthening the construction of teaching staff with the guidance of improving the "Double teachers" ratio}

In order to adapt to the construction of "new engineering" and improve the quality of talent training, local applied universities must formulate a practical planning for the development of teachers, further optimize the integration of the existing teachers and strengthen the construction of the "Double Teachers" teaching staff. In view of the standards and requirements of enterprises and industries, we should strengthen the training of students' technical skills and innovative entrepreneurial ability, which requires teachers' teaching ability to meet the requirements of professional posts. Therefore, local colleges and universities should analyze the present situation of teachers' structure seriously, adjust teachers' structure with corresponding measures and policies, combine the introduction and part-time work, adapt to the changing "new engineering" specialty construction, encourage the teachers with strong ability of application to obtain the corresponding qualification certificate of engineering teachers, and choose teachers in a planned way to join the enterprise training, post work and practical training, combine theory with practice, and constantly exercise the level of practical application of teachers in schools[5].

\section{E. Focusing on strengthening practical teaching, reforming teaching ways and methods}

At present, classroom teaching is the main carrier in our country. The training of compound innovative talents requires teachers to adhere to the combination of class and extracurricular, combination of class and engineering, and the combination of theory and practice. Theoretical courses should focus on the cultivation of students' ability to apply knowledge to practical production. Practical courses should attach importance to the relationship between theoretical knowledge and solution. Combining the knowledge elements and the requirements of the professional curriculum, we should actively promote the combination of theory and practice in teaching and teaching methods, and change the traditional injection into problem-based heuristic teaching. To strengthen the goal and motivation of professional learning, which tap the students' potential, stimulate their interest in learning, and cultivate their engineering application skills and to create innovative and entrepreneurial abilities[6].

\section{F. To strengthen the school enterprise cooperation as the platform, improve the cooperative education mechanism.}

In the face of the construction of "new engineering", local colleges and universities need to actively connect with regional economic development and industrial transformation, actively strengthen cooperation with industry enterprises, absorb more social forces and create a community of engineering education responsibility for co construction, co construction and sharing. Making full use of the teaching environment, teaching resources of enterprise and research institute, and their unique advantages in practice teaching to promote the combination of education and production, theory and practice. By guiding college students to participate in the project of production, learning and research, and changing the training mode of the closed education, the students will have more opportunities to go out of the school, go to the enterprises and move towards the practice of production research. In practice, it can stimulate innovation consciousness, cultivate innovative thinking and improve the ability of innovation. At the same time, it can enhance students' understanding of the profession, expand the perspective of students' social cognition, create more opportunities for practice and study for students, and enhance their comprehensive quality and social adaptability [7].

\section{CONCLUSIONS}

For Local Application-oriented Universities, positioning is the foundation of their development, and creating characteristics is an effective way for their development. Rational analysis of its own functional orientation, relying on its own advantages, should not pursue "tall" in the basic objectives of development planning, discipline construction and talent training, but should concentrate on limited resources, focus on regional economic and industrial development, grasp the direction of industry talents, and strive for a breakthrough in the knowledge structure, ability system, and cultural background of talents.

The construction of "new engineering" is a systematic project involving interdisciplinary departments and multi sectors and has global and complexity. It is impossible to wave it out and need the cooperation of the government, universities and enterprises to give full play to the advantages of the local applied undergraduate colleges and universities in the aspects of teachers, practical platforms and industry associations, 
which accomplish the "same frequency resonance" between schools and local economic and social development to a greater extent. According to the demand of the local industry, we should optimize the professional structure, open the school to the enterprise, cooperate with the school and enterprise, promote the integration of the production and education, and really pay attention to the training of the students' engineering practice and innovation ability, and explore a new way to adapt to the engineering education of the local applied undergraduate college.

\section{ACKNOWLEDGMENT}

This study was supported by the Teaching Quality Engineering Projects of Linyi University in 2014, 2016 and 2017.

\section{REFERENCES}

[1] X. Cai, and C. Sun, "The Construction of Training Quality Guarantee Mechanism of Application-Oriented Talents Under the Background of New Technology,” Journal of Yancheng Institute of Technology(Social Science Edition), vol. 30, no. 4, pp. 71-73, 2017.

[2] J. Zhao, Y. Xie, "Construction of Emerging engineering and Innovation of Engineering Education,” Research on Higher Engineering Education, no. 5, pp. 14-17, 2017.

[3] G. Lu, and T. LI, "Reflections of the Paths of Constructing and Developing Emerging Engineering Education,” Research on Higher Engineering Education, no. 3, pp. 20-26, 2017.

[4] Y. Wang, "Construction of Application-oriented Undergraduate Education System,” Heilongjiang Researches on Higher Education, no. 9, pp. 43-45, 2015.

[5] X. Shi, Y. Zhao, and X. Li, "The Thought of Constructing and Integration, Open and Self-adaptive System of Emergent Engineering Education for Local Universities," Research on Higher Engineering Education, no. 4, pp. 10-15, 2017.

[6] P. Chen, "Study on Current Situation Analyzing and Countermeasure of Innovative Ability Education of College Students," 3rd International Conference on Education and Social Development (ICESD 2017), pp. 500-504, April 8-9 2017, Xi’an, China.

[7] X. Zhou, "Discussion on the Integrated Teaching Mode of Industry and Education of Applied Universities," Journal of Higher Education, no. 8, pp. 23-24, 2017. 